\title{
The Influences of Grain Refiner, Inclusion Level, and Filter Grade on the Filtration Performance of Aluminum Melt
}

\author{
JIAWEI YANG, SARINA BAO, SHAHID AKHTAR, ULF TUNDAL, STIG TJØTTA, \\ and YANJUN LI
}

The addition of grain refiner particles in the aluminum melt is known to reduce the filtration efficiency of ceramic foam filter (CFF). In the present work, a systematic study on the influence of the addition level of Al-Ti-B master alloys and the inclusion level on the filtration performance of aluminum melt has been investigated by pilot-scale filtration tests using $50 \mathrm{PPi}$ and 80 PPi filters. The inclusion level of the melt has been measured using both LiMCA and PoDFA. For $80 \mathrm{PPi}$ CFF, the N20 inclusion (diameter larger than $20 \mu \mathrm{m}$ ) value in the post-filtrated melt does not increase when an ultra-high level of inclusions is introduced in the form of chips. For the melts with a low level of grain refiners $(\sim 0.5 \mathrm{~kg} /$ ton $)$, the filtration performance of $\mathrm{CFF}$ is not affected by grain refiners, regardless of inclusion load. An addition of $2.0 \mathrm{~kg} /$ ton grain refiners reduces the filtration performance for melts with a high inclusion level, where post-filtration inclusions with the size of $15-20 \mu \mathrm{m}$ were significantly increased. It is found, however, for the melts with an ultra-high inclusion load, the filtration performance of 80 PPi CFF is not affected by the grain refiner addition up to $2.0 \mathrm{~kg} / \mathrm{ton}$. The interactions between inclusions and grain refiner particles and the filtration mechanism have been studied by characterizing the spent filter and measuring the pressure drop during the filtration process. It is revealed that the strong adherence between oxide film with grain refiner particles dominates the grain refiner influence on the filtration performance of CFF. During the filtration process, oxide films have strong influences on the capturing of other inclusions such as oxide particles and $\mathrm{TiB}_{2}$ particles by the filter. A mechanism based on the interactions between oxide films and grain refiner particles is proposed to explain the CFF performance under the influence of grain refiner.

https://doi.org/10.1007/s11663-021-02310-7

(C) The Author(s) 2021

\section{INTRODUCTION}

AN aluminum melt of high cleanliness, namely a less content of contamination, is crucial for the metal quality of aluminum castings, the subsequent thermomechanical processes, and the mechanical properties of final products. The most common contaminants in aluminum melt include dissolved gasses (hydrogen), alkali and alkaline earth elements, a variety of intermetallic compounds, and nonmetallic inclusions, for instance, oxides,

JIAWEI YANG and YANJUN LI are with the Norwegian University of Science and Technology, 7491 Trondheim, Norway. Contact e-mail: yanjun.li@ntnu.no SARINA BAO is with the SINTEF Industry, 7465 Trondheim, Norway. SHAHID AKHTAR is with the Research and Development Karmøy, Norsk Hydro, 4265, Håvik, Norway. ULF TUNDAL and STIG TJØTTA are with the Hydro Aluminum Primary Metal, Commercial Technology, Romsdalsvegen 16600 Sunndalsøra, Norway.

Manuscript submitted on April 22, 2021; accepted August 20, 2021.

Article published online September 21, 2021. carbides, borides, nitrides, etc. ${ }^{[1]}$. These contaminants may come from the refractory material, raw material during the electrolysis, or even during the refining process. $^{[2]}$

Different methods such as sedimentation, bubble flotation ${ }^{[3,4]}$ fluxing, ${ }^{[5]}$ electromagnetic separation techniques, ${ }^{[6]}$ centrifugal separation, ${ }^{[7]}$ and filtration ${ }^{[8-24]}$ have been studied to remove the inclusions from molten aluminum. Filtration of aluminum by ceramic foam filter (CFF) is one of the most used methods in the casting industry nowadays owing to its relatively low cost and high efficiency.

Besides the metal cleanliness, a fine equiaxed grain structure will help to reduce the defects during the casting process and improve the processability and mechanical properties of aluminum alloys. This can be realized by adding grain refinement master alloys in the alloys, such as Al-3Ti-1B, Al-5Ti-1B, or Al-3Ti.0.15C, etc., which contain a large number of potent inoculant particles like $\mathrm{TiB}_{2}$ and TiC. Unfortunately, it is known 
that the addition of grain refiner particles reduces the filtration efficiency of aluminum melt with a heavy load of inclusions by CFF filtration.

The reduction of CFF filtration efficiency by grain refinement was reported by Towsey et al. ${ }^{[25]} \mathrm{A}$ systematic investigation on the filtration efficiency of AA 1050 aluminum melt by using $50 \mathrm{PPi} \mathrm{CFF}$ with various grain refinement master alloys (Al-Ti-B, Al-Ti-C) was made by Towsey et al. ${ }^{[25,26]}$ It was shown that the reduction of filtration efficiency by grain refiners only happened under a "high inclusion load" (N15 values in the range of 6 to $28 \mathrm{k} / \mathrm{kg}$ melt in their experiments), while the filtration efficiency remains unaffected under "low inclusion load" (N15 value below $2 \mathrm{k} / \mathrm{kg}$ ). It was also found that the $\mathrm{Al}_{3} \mathrm{Ti}$ intermetallic phase alone without $\mathrm{TiB}_{2}$ particles does not harm the filtration efficiency. Increasing the inclusion load does not harm the filtration efficiency either when grain refiners were absent. Therefore, the grain refiner particles were supposed to be the reason for filtration efficiency reduction. They pointed out that the inclusions can form a "bridge" at the filter window, which increases the filtration efficiency by changing the filtration mode from a less efficient depth mode into a more efficient cake mode. They suggested that the grain refiner particles could destroy or prevent the formation of the inclusion bridge, which, therefore, caused the reduction of filtration efficiency. The supporting evidence was that the inclusion bridges could not be found anymore in the spent filter when grain refiners were introduced.

However, how the inclusion bridge forms and how the grain refiner particle destroys the bridge remain unknown. Based on the figures shown by the authors, the inclusion bridge seems to be composed of inclusion particles in both CFF and Metaullics Tube Cartridge Filter (MCF). ${ }^{[24,27]}$ A similar reduction of filtration efficiency caused by the addition of grain refiners was also observed by Ray et al. ${ }^{[12]}$ By investigating the spent filters, inclusion bridges composed of inclusion particles were also observed. Laé et al. ${ }^{[28]}$ reported a similar filtration efficiency reduction for 5182 alloys filtrated by 50 PPi CFF after the grain refiner (Al-5Ti-1B) addition. They reported a loss of 42 pet filtration efficiency after grain refiner introduction and ascribed it to the prevention of oxide skin bridge formation by grain refiner particles. Duval et al.[19] also observed particle bridges in the spent CFF filter in their filtration experiment, where no grain refiners were added. Damoah et al. ${ }^{\left[{ }^{[3}\right.}$ showed that the inclusion bridge is composed of Fe-rich inclusion particles, covering the filter window in their spent filters. They found that the metal below the bridge is very clean; meanwhile, the inclusions were stopped by the bridge.

The present work is aimed at an in-depth understanding of the impact of grain refiners on aluminum filtration and the underlying mechanism. The influence of grain refiner addition levels, the filter grade (50 and 80 PPi CFF), and inclusion load on filter performance are investigated and discussed. Different from the particle bridge theory, a new explanation for why grain refiner reduces filter performance is given.

\section{EXPERIMENTAL}

\section{A. Material and Experiment Procedure}

Seven pilot trial filtration experiments were performed in the reference center of Hydro Aluminium Sunndalsøra, Norway. The CFF used were 50 and 80 PPi low phosphor alumina filters produced by Pyrotek with a dimension of $584 \times 584 \times 50 \mathrm{~mm}$. The compositions of the filter are as follows: $>70$ wt pct aluminum oxide, $0.5-1.5$ wt pet bentonite, and 1-10 wt pet aluminum phosphate. 6060 aluminum alloy was used with a composition of 0.4 wt pet $\mathrm{Si}, 0.17$ wt pet Fe, 0.001 wt pet $\mathrm{Cu}, 0.11$ wt pet $\mathrm{Mn}$, and 0.4 wt pet $\mathrm{Mg}$ and balanced with aluminum. The chips of the same alloy with the same chemical compositions were also intentionally added to increase the level of inclusions in the melt.

Nine tons of aluminum were melted in the melting furnace. By tilting the melting furnace, the liquid metal flowed into the launder from the outlet of the melting furnace and then flowed through the filter box, and thereafter, it returned to the melting furnace. The metal temperature in launder was held at approximately $730{ }^{\circ} \mathrm{C}$. By using the new Drain-Free Filtration (DFF) technology of Hydro, ${ }^{[29]}$ the filter was first primed from below, and then a normal filtration process began. The liquid in the melting furnace was removed at the end of each day.

After priming, two Liquid Metal Cleanliness Analyzers (LiMCA) II were placed before (Pos 1) and after (Pos 2) the filter, to give an online inclusion level analysis. After an approximate half-hour of filtration, 50 or $80 \mathrm{~kg} 6060$ alloy chip blocks were added directly into the melting furnace to increase the inclusion levels in the melt. Argon gas was used to stir the liquid metal in the furnace during the chips addition period. The metal pump was used to control the melt flow rate at approximately 7 tons/hour. In addition, two lasers were also positioned before and after the filter box, to monitor the metal height in the launder. Al-3Ti-1B grain refiner master alloy in form of the rod was introduced to the melt approximately 10 minutes after the chip addition was finished. In total, each filtration experiment lasted for approximately 1.5 hours. Hot PoDFA samples were taken before and after the filter to measure the inclusion types in the melt. A schematic drawing of the filtration loop used is shown in Figure 1.

An overview of the filtration experiments is shown in Table I. Since the metal was not changed during the day, the second experiment done on the same day will have some accumulation of grain refiner particles from the previous test. The grain refiner addition levels of test- 6 (after test-3) and test-7 (after test-5) are higher than the rest of the tests because of this reason. It is assumed that test- 6 contains $0.5 \mathrm{~kg} /$ ton grain refiner from the start of the filtration, and test-7 contains $2.0 \mathrm{~kg} /$ ton from the start. According to the measured average N20 inclusion values of the melt before filtration, the inclusion levels were classified as low $(0-3 \mathrm{k} / \mathrm{kg})$, high $(3-11 \mathrm{k} / \mathrm{kg})$, and ultra-high $(>11 \mathrm{k} / \mathrm{kg})$ in present work. 


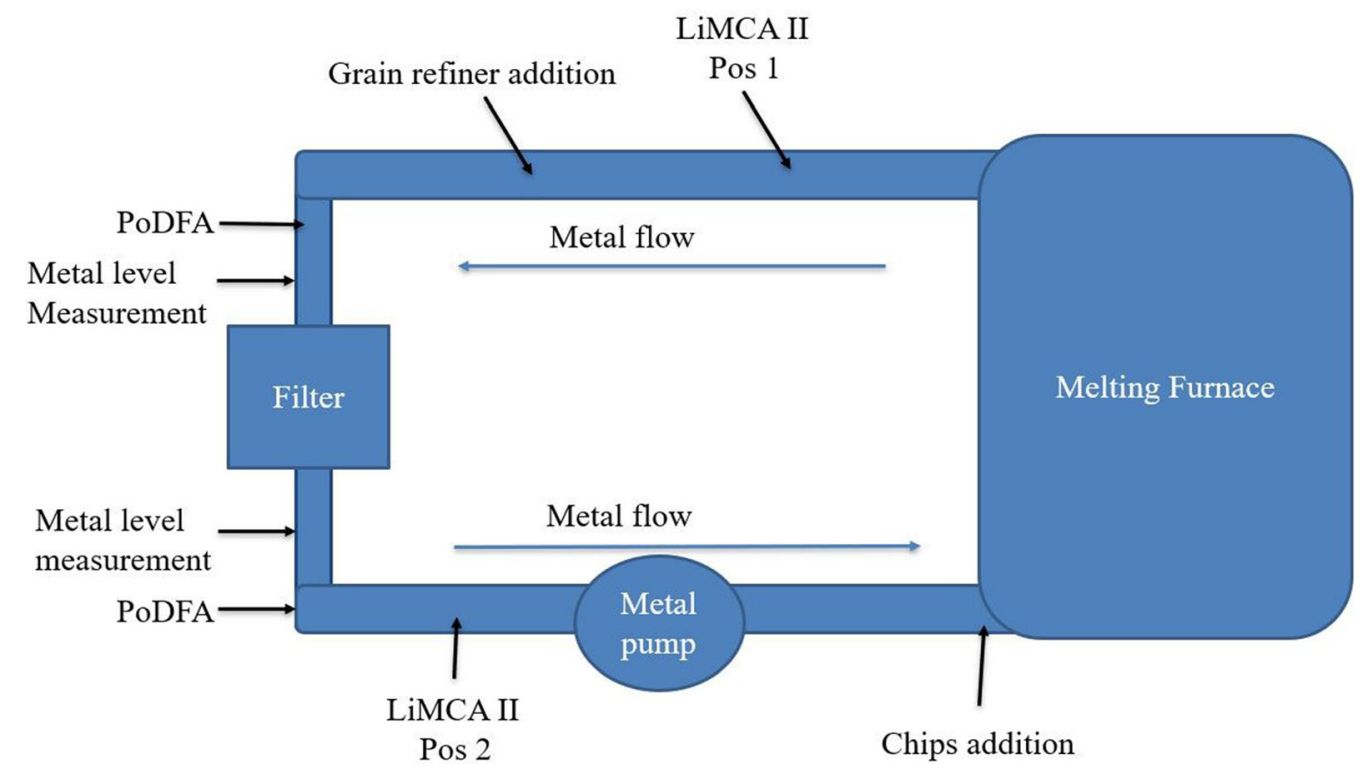

Fig. 1-Top view of the filtration loop.

Table I. Experimental Overview of Pilot-Trial Filtration Test

\begin{tabular}{lcccc}
\hline Test Nr & Chips Addition (kg/Batch) & Filter (PPi) & Grain Refiner Addition (kg/ton) & Average N20 Before Filtration (k/kg) \\
\hline 1 & 0 & 80 & 0.5 & 0.8 \\
2 & 50 & 80 & 0.5 & 4.5 \\
3 & 80 & 80 & 0.5 & 12.0 \\
4 & 50 & 80 & 2 & 9.9 \\
5 & 80 & 80 & $0.5-1$ & 22.3 \\
6 & 80 & 50 & $2-4$ & 12.4 \\
7 & 80 & 50 & & 27.7 \\
\hline
\end{tabular}

${ }^{1}$ These are measured values from LiMCA II during the experiment.

The spent filters with residual aluminum metal were cut, polished, and studied under Scanning Electron Microscopy (SEM) (SUPRA 55-VP, Zeiss, Oberkochen, Germany) with an Energy Dispersive x-ray Spectroscopy (Octane, EDAX, Mahwah, USA). An accelerating voltage of $10-15 \mathrm{kV}$ and a working distance of 10-15 $\mathrm{mm}$ were applied in the SEM observation.

Owing to the smaller pore sizes, it is easier for inclusion bridges (if any) to form in the $80 \mathrm{PPi}$ filters during filtration in comparison to the $50 \mathrm{PPi}$ filters. Therefore, more research focus has been put on the 80 PPi filters in present work.

\section{RESULTS}

\section{A. Influence of Grain Refiner at $0.5 \mathrm{~kg} /$ ton Level on 80 PPi Filter}

Figure 2(a) shows the LiMCA II analysis result of test-1 where no chips, but only $0.5 \mathrm{~kg} /$ ton of Al-3Ti-1B master alloy was introduced. Because of no chips introduction, the N20 counts for inclusions remained evenly at a low level with an average N20 of $0.8 \mathrm{k} / \mathrm{kg}$. N20 values before filtration are missing during 35 to 57 minutes due to adjustment of LiMCA II at position 1. As can be seen, when Al-3Ti-1B master alloy is introduced into the melt after 27 minutes of filtration, the inclusion counts after the filter do not show any increase. It seems that the addition of grain refiners at a low inclusion load does not harm the filter performance.

Figure 2(b) shows the LiMCA II result of test-2 where $50 \mathrm{~kg}$ chips are introduced into the melt. The inclusion load in the melt before the filter has a significant increase with the introduction of the chips, indicating a successful introduction of desired inclusions. The inclusion load before the filter gradually reduces to the level of $5 \mathrm{k} / \mathrm{kg}$ after chips addition is finished. The grain refiner rod is continuously fed into the melt with a constant adding rate of $0.5 \mathrm{~kg} /$ ton from 50 minutes. It is interesting to see that there is no change in the inclusion level in the post-filtration melt after the addition of grain refiners. It seems that the introduction of a grain refiner of 0.5 $\mathrm{kg} /$ ton does not reduce the filtration performance of 80 PPi CFF under a high inclusion load.

Figure 2(c) shows how low grain refiner addition level $(0.5 \mathrm{~kg} /$ ton $)$ impacts filter performance under a ultrahigh inclusion load (test-3). As can be seen, after the grain refiner is introduced into the melt at 50 minutes, 

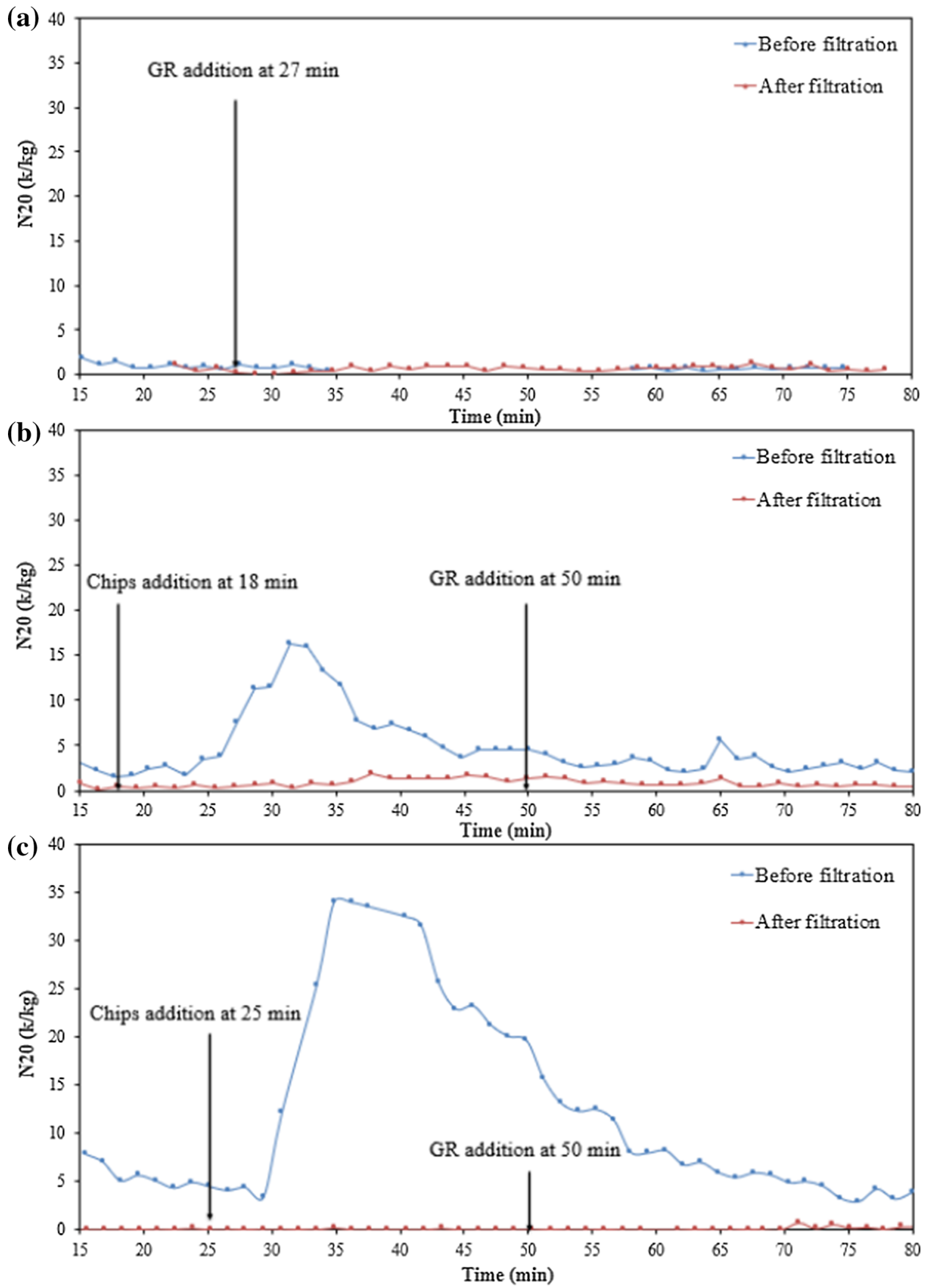

Fig. 2-LiMCA II measured N20 (inclusions over $20 \mu \mathrm{m}$ ) for both before and after $80 \mathrm{PPi}$ filter with a grain refiner addition level of $0.5 \mathrm{~kg} /$ ton. (a) No chips introduction (test-1), (b) $50 \mathrm{~kg}$ chips introduction (test-2), and (c) $80 \mathrm{~kg}$ chips introduction (test-3).

the N20 values after the filter remain the same as that before grain refiner addition. The fluctuation of N20 values at 70 minutes observed is due to the PoDFA sampling at 68 minutes, which brings oxide skin at the melt surface into the bulk of melt, disturbing the LiMCA measurement. 
These results show that a low level of grain refiner addition $(0.5 \mathrm{~kg} /$ ton $)$ does not seem to affect the $80 \mathrm{PPi}$ filter performance at any inclusion load. The N20 value after filtration is surprisingly lower for the melt with 80 $\mathrm{kg}$ chip addition (ultra-high inclusion load) than that with high and low inclusion load conditions. It implies that a higher inclusion load does not affect the filter performance, or even improves it.

\section{B. Influence of Grain Refiner at $2.0 \mathrm{~kg} /$ ton Level on 80 PPi Filter}

Figure 3 shows the influence of grain refiners on the filtration performance of $80 \mathrm{PPi} \mathrm{CFF}$ under two different inclusion load levels. As shown in Figure 3(a) (test-4), the N20 counts in the melt before filtration increases significantly after the introduction of $50 \mathrm{~kg}$ chips, while the N20 counts after filtration are very close to zero, showing that the filtration performance is not affected by the high inclusion load while most of the inclusions can be stopped by the filter. However, after the introduction of grain refiners at an addition level of $2.0 \mathrm{~kg} /$ ton at 50 minutes, the post-filtration inclusion load shows a remarkable increase, indicating a reduction of filter performance. It indicates that the grain refiner particles do reduce the filter performance for high inclusion load with an addition level of grain refiner particles as high as $2.0 \mathrm{~kg} / \mathrm{ton}$.

As shown in Figure 3(b), by adding $80 \mathrm{~kg}$ of chips, a higher and broader peak value of N20 before filtration is reached for test-5. After filtration, the nearly zero N20 value shows that a higher inclusion load does not reduce the filter performance when grain refiner particles are absent as well. Surprisingly, after an introduction of the same amount of grain refiners as test- 4 at 43 minutes, the N20 value after filtration keeps the same as before grain refiner addition. The impact of grain refiners on the N20 counts is undetectable. The inclusion level after the filter is low and stable regardless of grain refiner addition. It should be noted that the sharp increase of N20 value after filtration at 54 minutes was also caused by the PoDFA sampling. The above results confirm that under an ultra-high inclusion load, the addition of grain refiner does not affect the filter performance of $80 \mathrm{PPi}$ filter, even with an additional level as high as $2.0 \mathrm{~kg} / \mathrm{ton}$.
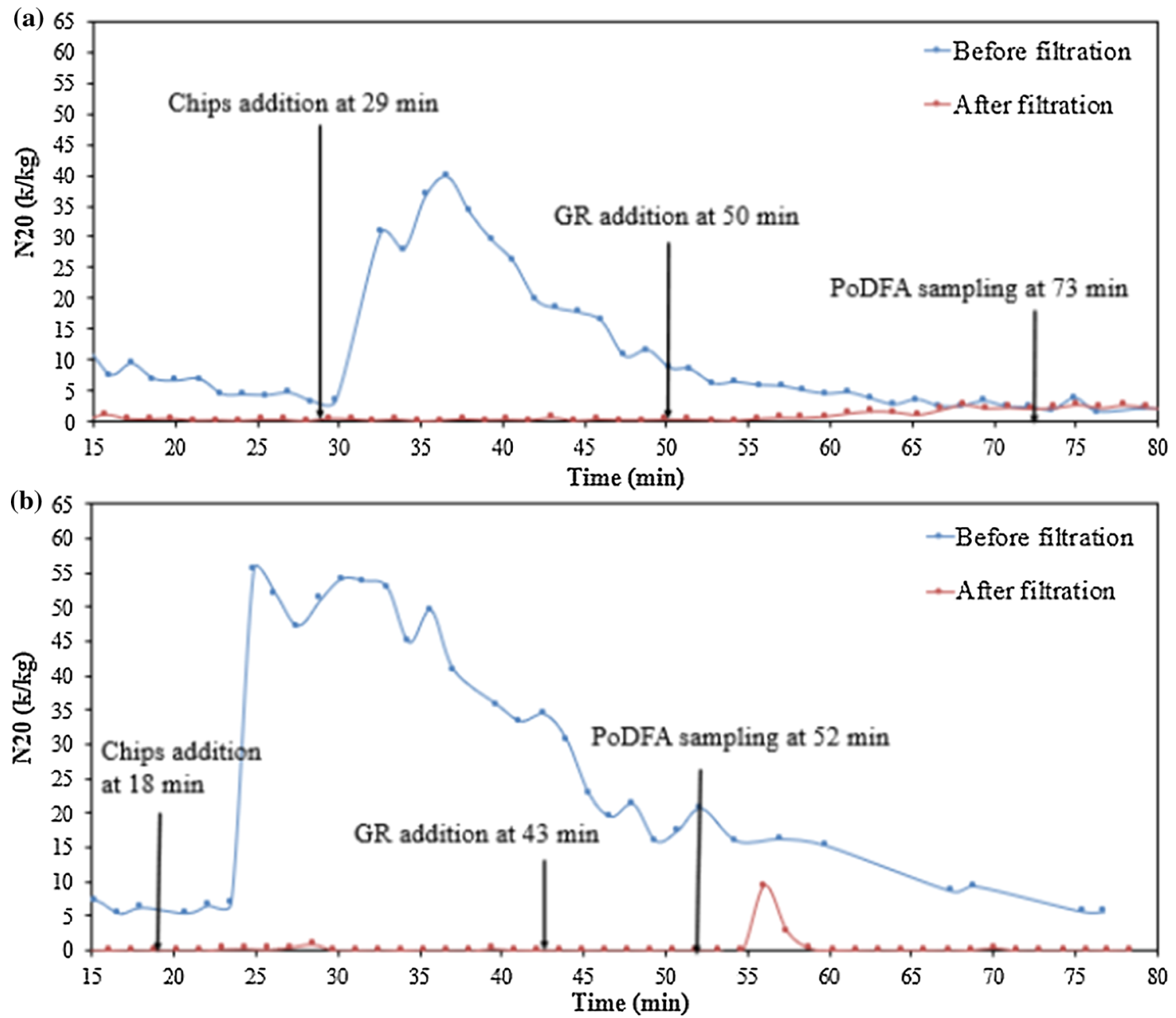

Fig. 3-LiMCA II measured N20 for both before and after $80 \mathrm{PPi}$ filter with a grain refiner addition level of $2.0 \mathrm{~kg} / \mathrm{ton}$. (a) $50 \mathrm{~kg}$ chips introduction (test-4), (b) $80 \mathrm{~kg}$ chips introduction (test-5). 


\section{Influence of Grain Refiner on Filtration Performance on 50 PPi Filter}

Figure 4(a) (test-6) shows the N20 counts of inclusions in the melt before and after filtration $v s$. times for a 50 PPi filter under ultra-high inclusion load $(80 \mathrm{~kg})$ with a grain refiner addition level of $0.5 \mathrm{~kg} /$ ton to $1.0 \mathrm{~kg} /$ ton. From 10 to 40 minutes, it shows the filtration behavior before and after the introduction of heavy load inclusion. As can be seen, before inclusion addition, the filtered melt contains a higher level of inclusion than the 80 PPi filter (average post-filtration N20 is approximately $2.7 \mathrm{k} / \mathrm{kg}$ in comparison to $0.1 \mathrm{k} / \mathrm{kg}$ in Figure 2(c), showing a lower filtration performance of $50 \mathrm{PPi} C \mathrm{CF}$ than $80 \mathrm{PPi}$. After the addition of heavily loaded inclusions into the melt at 18 minutes, there is a slight increase of the N20 counts after filtration than that before inclusion addition. This is different from the performance of $80 \mathrm{PPi} \mathrm{CFF}$, where an introduction of ultra-high load inclusion does not change the N20 value in the filtered melt (Figures 2(c) and 3(b)), implying that the filtration performance of $50 \mathrm{PPi} \mathrm{CFF}$ is more sensitive to the inclusion level in the melt. After further addition of $0.5 \mathrm{~kg} /$ ton Al-3Ti-1B into the melt, the N20 counts of inclusions after the filter keeps the same as before grain refiner addition. Similar to the 80 PPi filter, the performance of a $50 \mathrm{PPi}$ filter is not affected by the low addition level of grain refiner ( 0.5 to $1.0 \mathrm{~kg} /$ ton $)$ under an ultra-high inclusion load.

Figure 4(b) presents the N20 counts of inclusions $v s$. times for a 50 PPi filter under an ultra-high inclusion load $(80 \mathrm{~kg})$. The original aluminum melt is without chip addition and contains $2.0 \mathrm{~kg} /$ ton grain refiners until 38 minutes. As can be seen, a high post-filtration N20 count is observed from the start which indicates a poor filtration performance in comparison to the melt containing $0.5 \mathrm{~kg} /$ ton grain refiners (Figure 4(a)). By adding a high load of inclusion into the melt at 15 minutes, a significant increase of post-filtration inclusion counts can be observed. This shows that the filtration performance of 50 PPi filters has been severely affected by the addition of a high dosage of grain refiner particles. This is different from the results of $80 \mathrm{PPi}$ filter, the performance of which was not affected by either the introduction of ultra-high inclusion load or the addition of a high level of grain refiners (Figure 3(b)). It is also different from the filtration performance of $50 \mathrm{PPi}$ filter for the melt with $0.5 \mathrm{~kg} /$ ton grain refiner (Figure 4(a)).
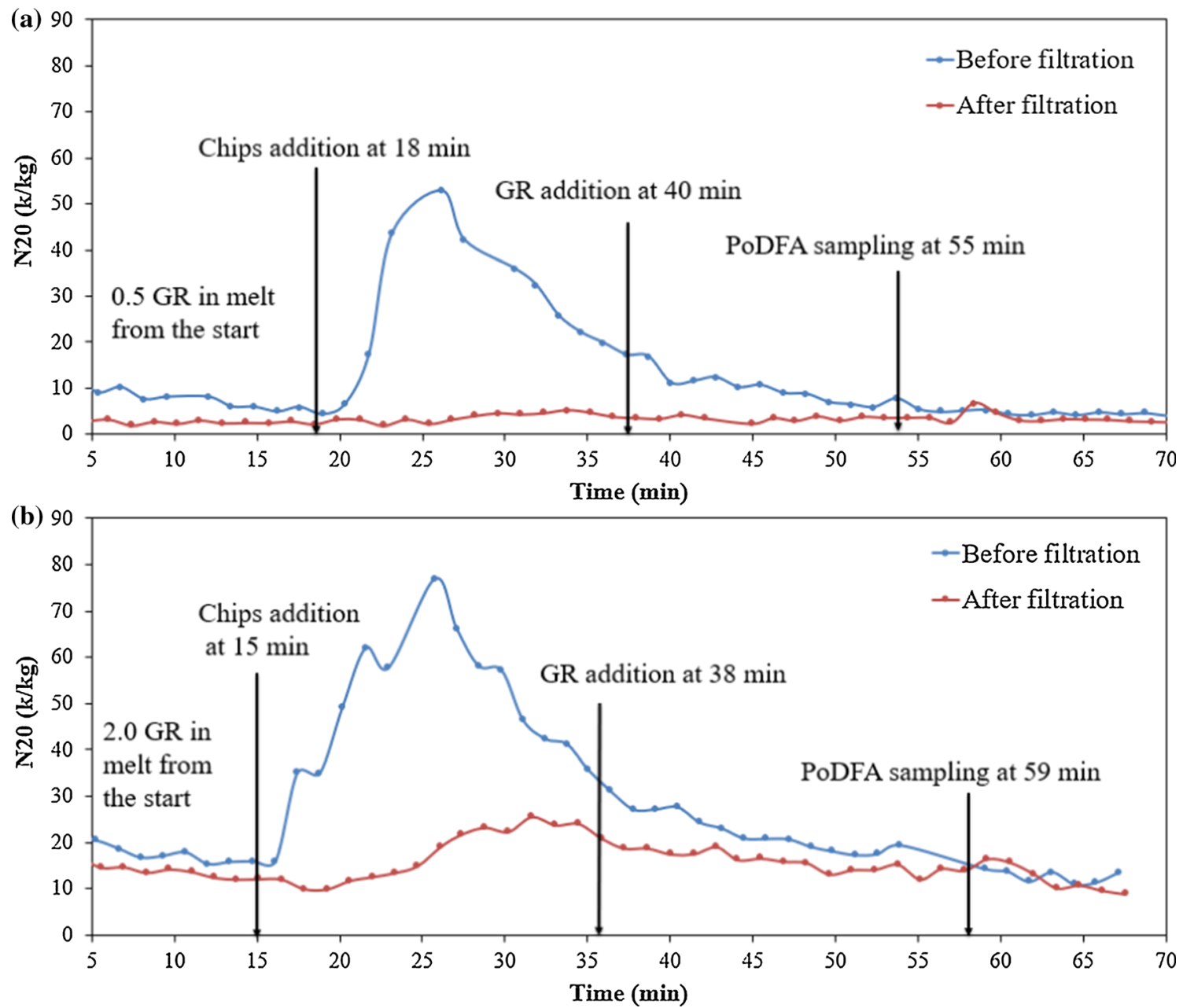

Fig. 4-N20 counts before and after 50 PPi filter with $80 \mathrm{~kg}$ of chips addition and a grain refiner addition level of $(a) 0.5$ to $1.0 \mathrm{~kg} /$ ton (test-6), (b) 2.0 to $4.0 \mathrm{~kg} /$ ton (test-7). 
However, with the further addition of $2.0 \mathrm{~kg} /$ ton grain refiner to the melt at 38 minutes, there is not any significant change of the post-filtration N20 counts. At 53 minutes, the performance of the filter reaches about the same as before heavy load inclusion was added. It seems that the further addition of grain refiner to 4.0 $\mathrm{kg} /$ ton level does not further increase the post-filtration N20 counts.

\section{Inclusion Types in the Melt Determined by PoDFA}

According to the PoDFA results shown in Table II, most of the inclusions in the melt can be identified as mixed oxides (mainly oxide films), $\mathrm{TiB}_{2} / \mathrm{Ti}$-rich inclusion stemmed from grain refiner, and a small amount of carbides and $\mathrm{MgO} /$ spinel. All PoDFA samples were taken after the grain refiner introduction. The inclusion filtration efficiency can be calculated based on Eq. [1].

$$
E=\frac{C_{\text {in }}-C_{\text {out }}}{C_{\text {in }}},
$$

where $C$ represents inclusion concentration either in area per $\mathrm{kg}\left(\mathrm{mm}^{2} / \mathrm{kg}\right)$ or number per $\mathrm{kg}(\mathrm{k} / \mathrm{kg})$. The subscript "in" stands for before filtration, and "out" for after filtration. Calculated filtration efficiencies are included in the last column of Table II. It is important to point out that the PoDFA analysis is not considered as a precise method to give quantitative values of inclusions in the melt, the calculated filtration efficiency only gives a relative trend of the inclusion removal. The big advantage of PoDFA is that it can be usd to identify the types of inclusions.

The PoDFA results show that test-3, 80 PPi filter with ultra-high inclusion load and low grain refiner addition level gives the highest total filtration efficiency, followed with Test-5 (80 PPi CFF, $80 \mathrm{~kg} /$ batch chips and $2 \mathrm{~kg} /$ ton grain refiner). The total filtration efficiencies of $80 \mathrm{PPi}$ CFF with ultra-high inclusion load (test-3 and test-5) are both higher than that with low and high inclusion load (test-2 and test-4). It indicates that a better removal efficiency can be reached by $80 \mathrm{PPi}$ filter under an ultra-high inclusion load condition, in comparison to the low or high inclusion load conditions. As expected, test-4 gives the worst filter performance in 80 PPi filters, which are the tests that are strongly affected by grain refiner introduction. This is in good agreement with the LiMCA N20 measurement results shown in Figures 2 and 3.

Test-7 (2.0 to $4.0 \mathrm{~kg} /$ ton grain refiner) shows a much lower total removal efficiency than test-6 (0.5 to 1.0 $\mathrm{kg} /$ ton grain refiner) with $50 \mathrm{PPi}$ filter, which confirms the strong influence of a high addition level of grain refiner particles on reducing the filtration performance of $50 \mathrm{PPi}$ filter. More $\mathrm{TiB}_{2}$ and mixed oxides for test-7 are also observed in the melt after the filtration, indicating the damaging effect of grain refiner particles on filter performance.

\section{E. Influence of Grain Refiner on Pressure Drop}

The lasers were used to measure the pressure drop over the filter during the filtration. When a fraction of filter pores are gradually blockaded by the inclusions, the flow resistance will increase inside the filter which will cause an increase in the pressure drop. A constant difference in metal height between the melts before- and post-filter means a smooth filtration process. Therefore, the change of pressure drop can provide useful information about the performance of filter

Figure 5(a) shows the evolution of pressure drop during filtration tests of $80 \mathrm{PPi}$ CFF with $0.5 \mathrm{~kg} /$ ton grain refiner addition under low, high, and ultra-high inclusion load conditions. As can be seen, the addition level of chips has a strong influence on the pressure drop of the filter. Without the addition of chips (test-1), the pressure drop of 80 PPi filter keeps constant. However, with the introduction of chips (test-2 and test-3), the pressure drop increases with increasing filtration time. The total increase in pressure drop is higher for the case with a higher addition level of chips. By comparing tests 1,2 , and 3 , it seems that the low addition level of grain refiners does not have any significant influences on the pressure drop.

Figure 5(b) shows the pressure drop change over time for $80 \mathrm{PPi}$ filter with a high grain refiner addition level $(2.0 \mathrm{~kg} /$ ton $)$ and an ultra-high inclusion load (test-5). As can be seen, the pressure drop increases with filtration

Table II. Summary of the PoDFA Results Regarding Inclusion Removal Efficiency

\begin{tabular}{|c|c|c|c|c|c|c|c|c|c|}
\hline \multirow[b]{3}{*}{ Test $\mathrm{Nr}$} & \multicolumn{7}{|c|}{$\begin{array}{l}\text { Inclusion Load } \\
\quad\left(\mathrm{mm}^{2} / \mathrm{kg}\right)\end{array}$} & & \multirow{3}{*}{$\begin{array}{l}\text { Total Filtration Efficiency } \\
\text { (Area Reduction Pct) }\end{array}$} \\
\hline & \multicolumn{2}{|c|}{ Mixed Oxides } & \multicolumn{2}{|c|}{ Carbides } & \multicolumn{2}{|c|}{$\mathrm{TiB}_{2} / \mathrm{Ti}-\mathrm{Rich}$} & \multicolumn{2}{|c|}{$\mathrm{MgO} /$ Spinel } & \\
\hline & Before & After & Before & After & Before & After & Before & After & \\
\hline 1 & 0.0123 & 0.0005 & 0.0070 & 0.0016 & 0.0158 & 0.0083 & no data & no data & 70.1 \\
\hline 2 & 0.0438 & 0.0195 & 0.0177 & 0.0083 & 0.0568 & 0.0278 & no data & no data & 53.0 \\
\hline 3 & 0.0589 & 0.0032 & 0.0098 & 0.00003 & 0.0245 & 0.00003 & 0.0049 & 0 & 96.7 \\
\hline 4 & 0.0126 & 0.0087 & 0.0002 & 0.0001 & 0.0082 & 0.0036 & 0 & 0 & 41.0 \\
\hline 5 & 0.0363 & 0.0047 & 0.0022 & 0.0026 & 0.0185 & 0.0026 & 0.0170 & 0.0005 & 86.0 \\
\hline 6 & 0.0225 & 0.0086 & 0.0020 & 0.0026 & 0.0164 & 0.0051 & 0 & 0.0009 & 59.9 \\
\hline 7 & 0.0156 & 0.0171 & 0.0039 & 0.0015 & 0.0507 & 0.0557 & 0.0078 & 0 & 4.7 \\
\hline
\end{tabular}



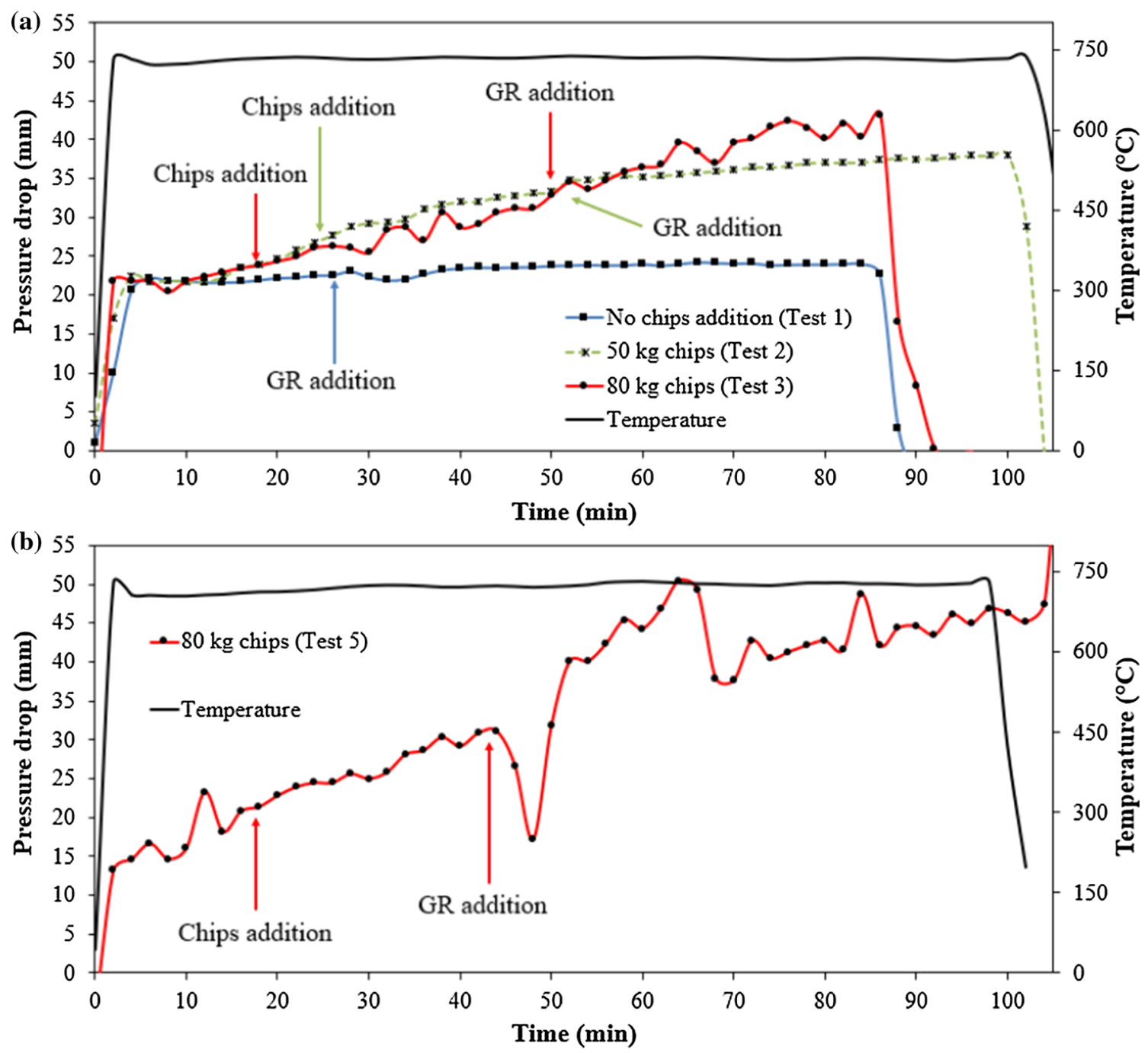

Fig. 5-The pressure drops of (a) an 80 PPi filter with 0 (test-1), 50 (test-2), and 80 (test-3) kg chips addition and with a grain refiner addition level of $0.5 \mathrm{~kg} /$ ton. (b) The pressure drops of an $80 \mathrm{PPi}$ filter with $80 \mathrm{~kg}$ chips addition and with a grain refiner addition level of $2.0 \mathrm{~kg} / \mathrm{ton}$ (test-5). The big variation of pressure drop in between 45 to 70 minutes is due to PODFA sampling and some other disturbance during experiments, which does not influence the general trend. The filtration temperature is $730{ }^{\circ} \mathrm{C}$.

time. This result agrees well with the LiMCA II measurement results where test-5 shows no decrease in filtration performance with grain refiner addition. Owing to the problem with laser measurement, the pressure drop of test-4 is not presented.

Figure 6 shows the evolution of pressure drop for filtration test of $50 \mathrm{PPi}$ filter under ultra-high inclusion load with two different grain refiner addition levels (test-6 and test-7). As can be seen, the pressure drops for the two tests are quite close and keep nearly constant with increasing filtration time. It implies that the added grain refiner particles and inclusions do not have any significant influence on the pressure drop of $50 \mathrm{PPi}$ filter. It is interesting to see that the maximum pressure drop of $50 \mathrm{PPi}$ filter $(<20 \mathrm{~mm})$ is much lower than that of $80 \mathrm{PPi}$ filter $(35-45 \mathrm{~mm})$ for melts with ultra-high inclusion levels, indicating that the pore size of the filter has a strong influence on the pressure drop.

\section{F. Inclusion and TiB $B_{2}$ Particles in the Spent Filter}

Figure 7 shows the SEM image of the spent filter of test-5, containing solidified aluminum melt. As can be seen, the top of the spent filter is covered by a layer of solidified aluminum, in which massive oxide films are agglomerating together and formed as cake layer (Figure 7(a)). EDS measurements of these oxide films suggest that they are Mg-rich aluminum oxide films. Figures 7(b) and (c) show magnified images of the cross-section of the top layer. Interestingly, a large number of $\mathrm{TiB}_{2}$ particles are tangled by the oxide films. Furthermore, some block-shaped alumina particles (pointed by arrows) can also be observed attaching to the oxide films. Figures 7(e) and (f) show the solidification microstructure at the inlet of the spent filter. At the surface of cake layer, massive grain refiner particles can also be seen agglomerated on the oxide films and the porous walls of the filter (Figure $7(\mathrm{~d})$ ). It has to be 


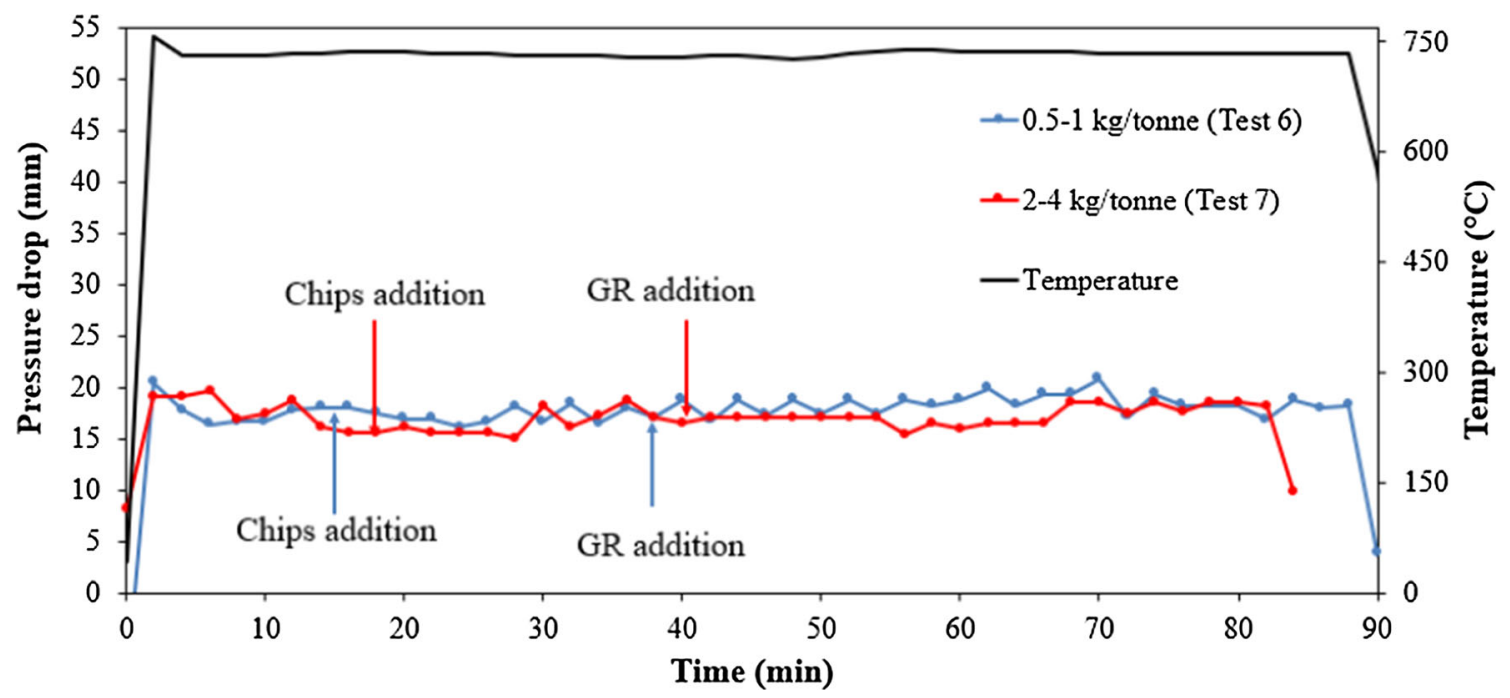

Fig. 6-The pressure drops of a $50 \mathrm{PPi}$ filter with $80 \mathrm{~kg}$ chips addition and with a grain refiner addition level of 0.5 to $1.0 \mathrm{~kg} /$ ton and 2.0 to 4.0 $\mathrm{kg} / \mathrm{ton}$.
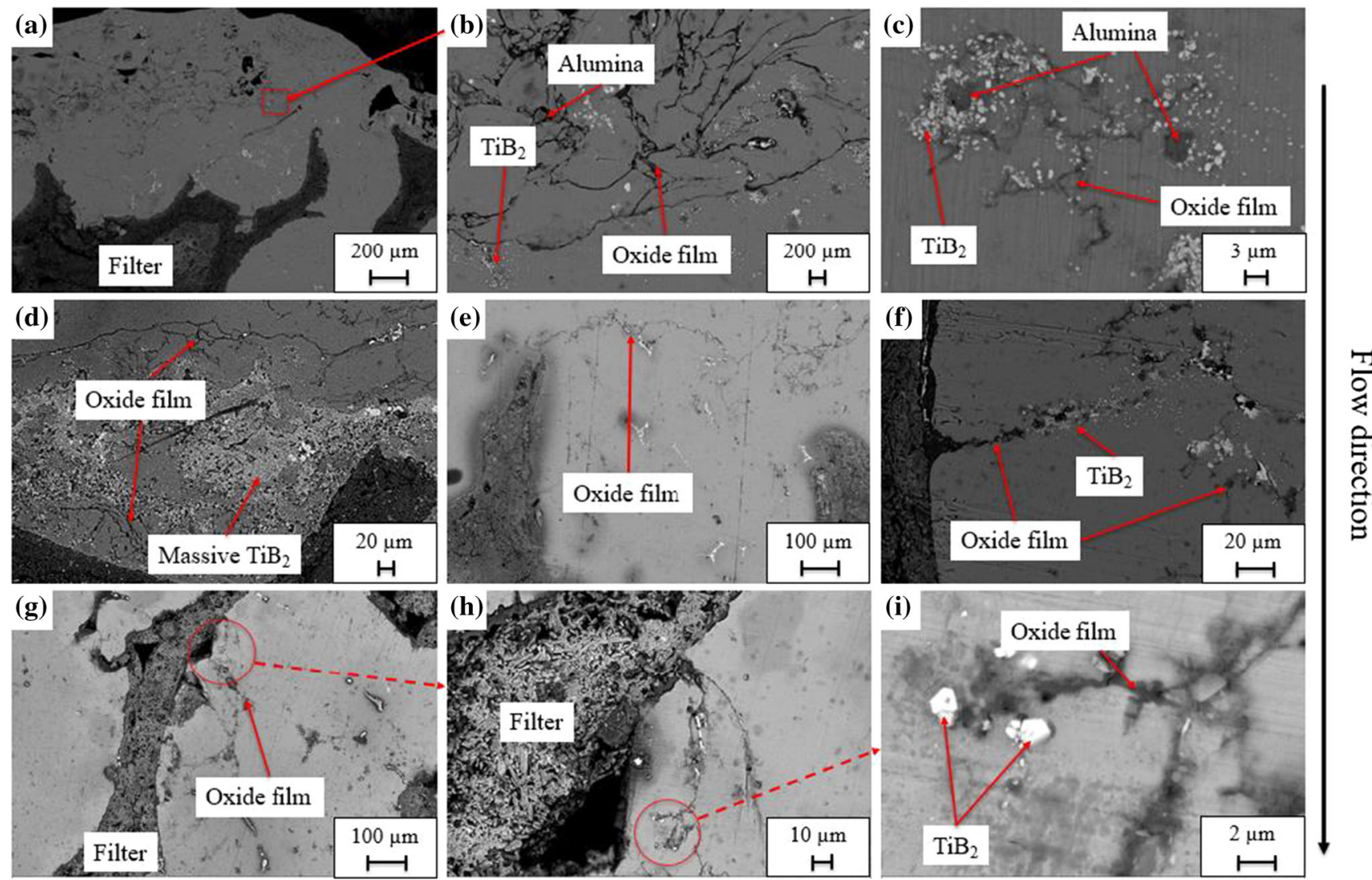

Fig. 7-The spent filter of filtration from test-5 under ultra-high inclusion load ( $80 \mathrm{~kg}$ chips), high grain refiner addition level (2 kg/ton) with an 80 PPi filter. (a) In the top section of the filter with inclusions above the filter. $(b)$ and $(c)$ The magnification of (a) where massive oxide films are found together with particles (alumina particles and $\left.\mathrm{TiB}_{2}\right)$. (d) closer look at the filter surface (screen), massive grain refiner, and oxide films were agglomerated and deposited on the alumina filter. $(e, f)$ The inlet of the filter where oxide films narrow the window and are attached to the filter wall by one of the ends where another end tangled with the inclusions. ( $g$ through $i$ ) The bottom section of the filter, where oxide films can still be found which attached to the filter wall.

mentioned that large efforts have been spent to search for the so-called "inclusion bridges" in the spent filter. Unfortunately, no inclusion bridge across the whole window of any porous could be found. Figure 7(e) shows a porous opening at the upper surface of the filter. It is interesting to see that some oxide films are nearly crossing the whole opening, which looks like an "inclusion bridge". But the oxide films have only one end 


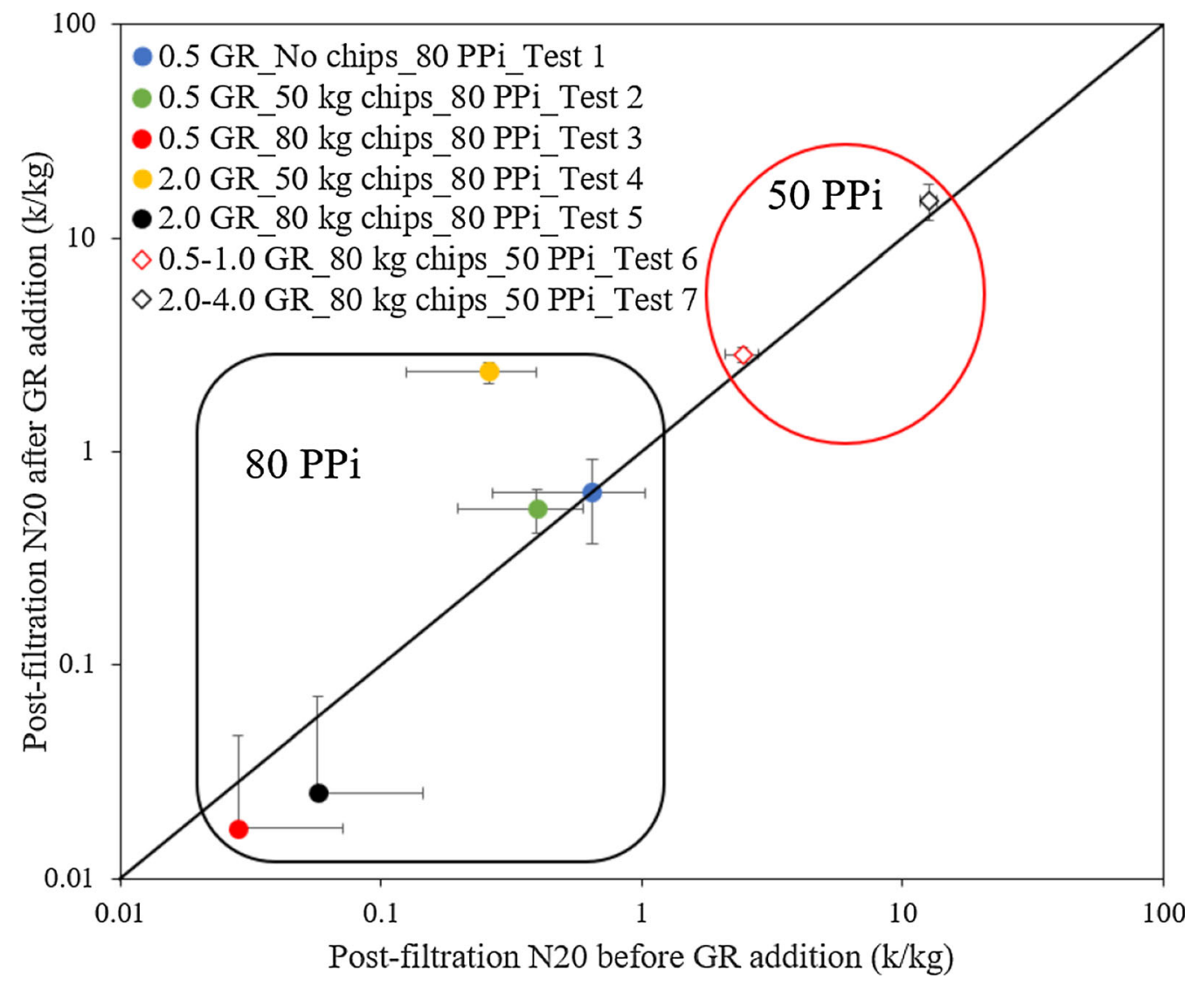

Fig. 8- Comparison between post-filtration N20 value before and after grain refiner addition. Values above the diagonal line hint ruined filtration performance due to the addition of grain refiner and vice versa.

connecting to the porous wall, while the other ends are floating in the melt. Figure 7(f) shows another porous in the filter, where oxide films with only one end adhering to the porous wall can also be seen and a large number of $\mathrm{TiB}_{2}$ particles are adhered to the oxide film. Such "seaweed" like oxide films adhered by $\mathrm{TiB}_{2}$ particle can be found in the whole filter. However, the large oxide films are mainly found in the top layer of the filter (about $2 \mathrm{~mm}$ in thickness). i.e., at the cake and inlet. With increasing distance from the upper surface, there are fewer oxide films and grain refiner particles in the filter.

Figures $7(\mathrm{~g})$ through (i) show the bottom part of the filter. As shown in Figure 7(g), the solidified aluminum grains in the porous at the bottom of the filter contain less larger inclusion compared to the top region. Nevertheless, $\mathrm{TiB}_{2}$ particles trapped by the seaweed-like oxide films can still be found (Figures 7(h) and (i)).

The solidification structure of $50 \mathrm{PPi}$ spent filters are also examined, which is similar to the $80 \mathrm{PPi}$ spent filters. A major difference is that a little solidified aluminum layer could be found on the top of the $50 \mathrm{PPi}$ spent filter. Otherwise, seaweed-like oxide films adhered with grain refiner particles can also be found in the spent filter.

\section{DISCUSSIONS}

\section{A. The Effect of Grain Refiner on Filter Performance}

Equation [1] is often used to quantitatively assess the filtration performance during the industrial filtration process of a large volume of aluminum melt with nearly constant inclusion load before filtration. However, this equation is less sensitive for the aluminum melt with changing inclusion load as in the present study. For example, for the filtration case shown in Figure 2(b), the equation may give a reducing filtration efficiency with time, because $C_{\text {in }}$ reduces with time owing to no further feeding of chips, while $C_{\text {out }}$ remains almost unchanged. This does not represent the real filter performance. Therefore, a direct comparison between $C_{\text {out }}$ before grain refiner addition and $C_{\text {out }}$ after grain refiner addition is used to evaluate the filter performance. In order to minimize the effect of $C_{\mathrm{inn}}$, the $C_{\text {out }}$ values are obtained by averaging 10 minutes filtration period of time, where the $C_{\text {inn }}$ levels are similar before and after grain refiner introduction. Figure 8 shows the comparison results where both the $y$ and $x$-axis are log scaled. Due to the qualitative nature of PoDFA analysis, the calculated filtration efficiency data shown in Table II are not included in this figure. 
As can be seen, the post-filtration inclusion level after $80 \mathrm{PPi}$ filter is much lower than $50 \mathrm{PPi}$ filter, indicating a better performance of filters with smaller pore size. For 80 PPi filter filtration of aluminum melt without chips addition, an addition of $0.5 \mathrm{~kg} /$ ton grain refiner does not affect the filtration performance at all, and the data point (test-1) is locating at the diagonal line. With an addition of $50 \mathrm{~kg}$ chips (test-2, N20 $=4.5 \mathrm{k} / \mathrm{kg}$ ), a slight reduction in filtration performance by $0.5 \mathrm{~kg} /$ ton grain refiner addition can be observed. However, after addition of $80 \mathrm{~kg}$ chips (test-3, N20 $=12.0 \mathrm{k} / \mathrm{kg}$ ), the filter performance seems slightly increased. Since all the data points are very close to the diagonal line, the $0.5 \mathrm{~kg} / \mathrm{ton}$ grain refiner addition can be considered to have a neglectable effect on the filtration performance. For the $2.0 \mathrm{~kg} /$ ton addition level of grain refiner, the filtration performance is significantly reduced for the melt with 50 $\mathrm{kg}$ chips addition (test-4, N20 $=9.9 \mathrm{k} / \mathrm{kg}$ ). The reduction of filtration performance of CFF by grain refiner addition under a "high" inclusion load was commonly observed in previous research work. ${ }^{[12,25,26,30]}$ When the inclusion load is further increased from "high" to "ultra-high" level (test-5, $80 \mathrm{~kg}$ chip addition, $\mathrm{N} 20=22.3 \mathrm{k} / \mathrm{kg}$ ), the filtration performance is not affected by the grain finer addition, which is a new finding. If comparing to the post-filtration inclusion level of melt with no chip addition (test-1) and $50 \mathrm{~kg}$ chip addition (test-4), the filter performance is substantially improved by the addition of an ultra-high load of inclusion (test-3 and test-5). This result is also consistent with the PoDFA results shown in Table II. Thus, the inclusion load has a strong influence on the post-filtration melt cleanliness when filters with smaller pore sizes are used. This is because an ultra-high inclusion load caused the formation of the cake layer at the top window of CFF and the cake filtration mode becomes the dominant filtration mechanism for the filter, which provides superior filter performance. If we compare test-3 and test-5, it can be seen that $0.5 \mathrm{~kg} /$ ton grain refiner addition gives a better filtration performance than $2.0 \mathrm{~kg} /$ ton grain refiner addition.

For $50 \mathrm{PPi}$ filter, similar to $80 \mathrm{PPi}$ filter, a higher grain refiner addition level leads to a higher post-filtration inclusion level (test-6 and test-7). Moreover, results from the present work also show that further addition of grain refiners from 0.5 to $1.0 \mathrm{~kg}$ /ton (test-6) or 2.0 to 4.0 $\mathrm{kg} /$ ton (test-7) does not make the filtration performance worse. By comparing the results from both tests, it can be concluded that the amount of grain refiner particles plays an important role in the filtration performance of 50 PPi filters. Generally, a high grain refiner addition level causes poor filter performance.

For a long time, the filtration efficiency reduction by grain refiners has been explained based on the inclusion bridge theory, where grain refiner particles were supposed to destroy or prevent the formation of inclusion bridges. By a careful characterizing of the microstructure of spent filters of $50 \mathrm{PPi}$, no particle bridges have been found on the top or inside the filters in the present work with grain refiner addition. Also, test-5 shows that an addition of high level of grain refiners does not reduce the $80 \mathrm{PPi}$ filter performance under an ultra-high inclusion load condition. This implies that the inclusion particles bridge mechanism of filtration may not be able to explain the reduced filtration performance by grain refiner particle addition.

\section{B. The Role of Oxide Films During Filtration}

Since the major content of the inclusion introduced by the chips are oxide films, the behavior of oxide films during the filtration process has to be clarified. The filtration of melt is usually considered to be realized by several modes, namely, depth mode, sieve mode and cake mode. ${ }^{[31,32]}$ The depth mode or standard blocking filtration happens when the particle sizes of inclusions are smaller than the pore sizes, yet, the inclusions were still be captured by the filter owing to the complex structure of the filter and surface adhesion. The sieve mode occurs when the particles are larger than the filter pores, thus, sieved by the filter. Sieve mode can transform into the cake mode over time, owing to the more accumulation of inclusions at the filter surface screen. Such inclusion accumulation leads to an increase in filter performance since the real filter pores size is now reduced by the accumulated inclusions.

Additionally, it was suggested that blocking of filter pore by inclusion particles smaller than the pore size can also occur by the so-called bridging mechanism. ${ }^{[32]}$ For CFF, once the inclusion "bridge" forms across the filter window, the filtration mechanism will be gradually changed from less efficient depth mode into more efficient cake mode. In fact, the formation of such bridges by particle inclusion as reported in References 8 , 12,33 is very difficult. Since the average pore size for 50 PPi and $80 \mathrm{PPi} \mathrm{CFF}$ are $623 \pm 120 \mu \mathrm{m}$, and $383 \pm 87$ $\mu \mathrm{m}$, respectively, ${ }^{[34]}$ while the majority of the inclusion particles (oxides and $\mathrm{TiB}_{2}$ particles) are lying between 0.2 and $10 \mu \mathrm{m}$, it is nearly impossible for individual particles to form bridges, covering the pore opening. Bridges can only form when large inclusion clusters composed of small particles pass through the pores of filter, the chance of which is rather low. Grandfield et al. ${ }^{[35]}$ also mentioned that the CFF pore size is too large for the inclusions to form a cake, especially with a typical industrial concentrations of $<10 \mathrm{ppm}$ of inclusions. This may explain why no inclusion particle bridge has been observed in any of the spent filters in this work.

On the other hand, the size of oxide films is in the range of 10-5000 $\mu \mathrm{m} .{ }^{[36]}$ Some of the oxide films which are larger than the size of pores may have a chance to cover the pores, forming bridges. However, with the limited strength of oxide films, the bridges can be easily destroyed by the melt flow. Instead, there is a much larger chance for oxide films to have one end adhering to the pores wall, while the other end keeps floating inside the pores, like "seaweed" in the sea. Under such a condition, these oxide films can capture inclusion particles, grain refiner particles and new oxide films. With the agglomeration of more particles onto the oxide films, the seaweed-like oxides may detach from the pore wall due to the gravity effect and flow into a new pore. The existence of the "seaweed" like oxide films on the wall can significantly increase the chance for the small 
inclusion particles to be captured by the filter, and therefore increase the efficiency of depth mode. As shown in Figure 7, oxide films adhered by inclusion particles and grain refiner particles are distributing throughout the whole filter in $80 \mathrm{PPi}$ filter. This is similar to $50 \mathrm{PPi}$ filter. Such seaweed form oxide film was also observed by Duval et al. ${ }^{[19]}$ but recognized as an inclusion bridge.

The capturing of small inclusion particles by oxide films can be attributed to the strong adherence between the particles and the films. In a previous wetting test study, we have shown that the $\mathrm{TiB}_{2}$ particles tend to agglomerate onto the oxide skins of aluminum droplets. In fact, not only $\mathrm{TiB}_{2}$ particles but the $\mathrm{TiC}$ particles were also captured by the oxide skins. ${ }^{[37]}$ In another research work, we have shown that both oxide particles and $\mathrm{TiB}_{2}$ particles tend to adhere to oxide films in the aluminum melt at $750{ }^{\circ} \mathrm{C} \cdot{ }^{[38]}$ It is confirmed that the oxide films + oxide particles or $\mathrm{TiB}_{2}$ particle clusters are not formed during the solidification process but under the liquid states. This confirmed that the Mg-containing aluminum oxide films have a very strong ability to catch the oxide particles and $\mathrm{TiB}_{2}$ particles in the liquid melt. Therefore, it is safe to propose that if any inclusion particle bridges could form in the CFF, the oxide films should have played an important role, in bonding the particles together.

The oxide films have a distinct morphology from particle inclusions. It is known that the shape factor of an inclusion particle has a major influence on the particle settling and their motion in the $\mathrm{Al}$ melt, where oxide films have a very low settling speed and the bifilms even wrapped in gases which provide the buoyancy forces and resulting in floating at the top layer of the melt. ${ }^{[38,39]}$ Instead of distributing homogeneously in the melt, the oxide films prefer to agglomerate together to reduce their surface area with the melt and thereby reduce their surface energy. These large oxide films can be tangled with each other and capture the small inclusions, thus, improves the filter performance. Compared with the particles, these oxide films seem to be more reasonable and are easier to block the filter pores partially or even totally.

When the level of oxide film inclusions in the melt is high enough while the pore size of filter is small (for instance $80 \mathrm{PPi}$ ), it is possible for the oxide films covering the top screen of filter to survive and develop into a thick cake layer due to the accumulating of the oxide films. Therefore the filtration mechanism is dominated by the cake mode. This is exactly the case shown in Figure 2(c). The formation of such cake layer will significantly increase the flow resistance of the CFF, resulting in an increase of pressure drop (Figure 5). For $80 \mathrm{PPi}$ filter, a significant increase of pressure drop with filtration time has been observed.

Interestingly, no increase in pressure drops has been observed for the $50 \mathrm{PPi}$ filter, yet the filter performance is reduced for the case with high addition level of grain refiner, while it remains the same for the low grain refiner addition level. The nearly constant pressure drop indicates that the formation of cake layer for $50 \mathrm{PPi}$ filters is difficult, while the depth mode should have played a more important role during the filtration process, especially with the help of "seaweed" like films.

\section{The Filtration Mechanism with Grain Refiner Particles}

During the filtration process, the inclusions in melt are transported and trapped by the obstacles in the filter and thereby filtrated from the melt. The chance for inclusion to be stopped by CFF during filtration is determined by the transportation behavior or collection mechanism between inclusion and obstacles inside the filter, which can be summarized as: direct interception-inclusion hits the filter surface following the fluid flow lines, gravity force-inclusion with a specific density different from the melt leaves the fluid flow line owing to gravity, Brownian movement, inertial forcesthe inclusion proceed in a straight line owing to its own inertia, and hydrodynamic effects - inclusion hit the filter wall due to the different fluid velocity near the filter wall caused by friction. ${ }^{[17,31,36,40,41]}$

The gravitational number and the interceptional number are considered as the two most important parameters for the transportation of inclusions inside the filter. ${ }^{[19,21,35]}$ The interceptional number indicates how easy particles are intercepted by the filter. With increasing the content of oxide films in the filter, either forming bridges or adhering onto the wall of filter pore, the interceptional number increases. Therefore, it can be expected that a high content of oxide film inclusions in the melt will increase the filter performance for the alloys with no or low-level addition of grain refiners. This is consistent with the experimental results shown in Figure 2, and the observation of Duval et al. ${ }^{[19]}$ However, when a high level of grain refiner particles are added into the melt, the $\mathrm{TiB}_{2}$ particles are continuously captured by oxide film bridges and "seaweed" like oxide films. With increasing weight, the oxide film bridges may be broken, while the seaweed-like oxide films will detach from the filter wall. As a consequence, these films agglomerated with other inclusion particles and $\mathrm{TiB}_{2}$ particles may re-enter the melt which causes a decrease in filter performance.

Besides the interception number, the gravitational number, which indicates the influence of gravity on inclusions, has an important impact on the filter performance as well, ${ }^{[19,21]}$ based on a $2 \mathrm{D}$ lattice-Boltzmann model calculation.

When the inclusions are heavier than the melt, they have a large positive gravitational number which makes them able to settle on the pores wall of the filter easily. For those inclusions with a large negative number, they will be floating toward the surface of the melt. The filter performance is high when the gravitational number is either very high (large positive value) or very low (large negative value). The filter performance will decrease if the gravitational number of inclusions close to zero (i.e., have a similar density with the melt). In other words, if the inclusions in melt have a huge density difference with the melt, it is easier for them to be separated from the melt by the filter. 
The grain refiner particles have a large gravitational number since they have the highest densities among all the common inclusions in melt, ${ }^{[42]}$ whereas the large oxide films have a negative gravitational number. When these two types of inclusions separately existed, the filter performance is believed to be high. This fits well with the general observation that the filters have a good performance without or with a low addition level of grain refiners. However, the oxide films will capture other inclusion particles. By collecting these particles, the density of the film will increase (the films and particles are now considered as a new inclusion cluster) which results in a counterbalance in gravitational number. As result, the inclusion cluster with a gravitational number close to zero will have a lower filter performance. This explains why the $50 \mathrm{PPi}$ filter performance is not affected when the grain refiner addition level is low, since the gravitational number of the mixed inclusion is less affected owing to insufficient grain refiner particles. While it is more severely affected when the grain refiner addition level is high under an ultra-high inclusion load. For the filtration of aluminum melt with an ultra-high amount of inclusions by $80 \mathrm{PPi}$ filter, the thick cake layer composed of oxide films can block most of the $\mathrm{TiB}_{2}$ particles at the top of the filter. Therefore, a high addition level of grain refiners does not affect the seaweed-like oxide films in the bulk of CFF. A simple schematic is drawn in Figure 9 to show the influences of oxide films and grain refiner particles on the CFF.

Besides these two influences of grain refiners on filter performance, the detection limit of LiMCA II should also be considered, since LiMCA II cannot detect particles smaller than $15 \mu \mathrm{m} .{ }^{[43,44]}$ Most $\mathrm{TiB}_{2}$ grain refiner particles have diameters in the range of $0.1-2$ $\mu \mathrm{m},{ }^{[45]}$ and are too small to be detected by LiMCA II. Furthermore, it is also difficult for the $\mathrm{TiB}_{2}$ particles to agglomerates into clusters larger than $15 \mu \mathrm{m}$ by themself, especially in the flowing melt. This results that the LiMCA usually cannot detect grain refiners as inclusions. However, $\mathrm{TiB}_{2}$ particles can be easily captured by

(a)

Top of the filter

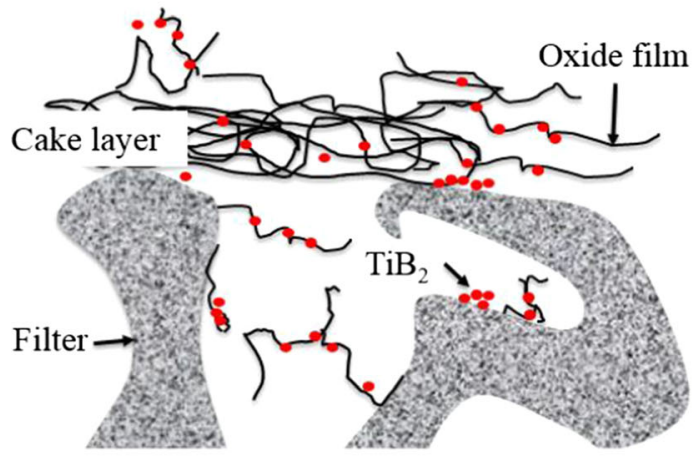

oxide films at the top or in the bulk of the filter, forming large inclusion clusters. If they are not captured by the filter, they will survive the filtration and be detected as inclusions by the LiMCA. Since smaller inclusions have more chance to flow through the filter pores, it can be expected that the post-filtration inclusions are dominated by small inclusions. Figure 10 shows the evolution of post-filtration inclusion counts classified into different size ranges $15-35 \mu \mathrm{m}$, for test-4 (80 PPi). The filtration performance was significantly reduced by the grain refiner addition. As can be seen, the post-filtration inclusions of all detected size classes show a clear increase after grain refiner addition. The vast majority of the inclusions have sizes lying between 15 and $20 \mu \mathrm{m}$. This confirms our previous explanation. In the case where grain refiner does not affect the filter performance, for example, test-5, no increase of specific size class can be observed after the grain refiner addition. This also explains why the addition of a low level of grain refiner particles alone does not affect the filter performance in a clean melt or under a very low inclusion load.

\section{CONCLUSIONS}

Seven pilot trail filtration tests are conducted in order to investigate the effect of grain refiner on the filtration behavior of CFF. The following conclusions can be withdrawn:

1. Higher filter performance was observed for $80 \mathrm{PPi}$ in comparison to $50 \mathrm{PPi}$ filter. When grain refiner particles are absent or at a low addition level, an increase of inclusion load seems to increase the filtration performance and the pressure drop by time for $80 \mathrm{PPi}$ filters. 50 PPi filters do not show any significant increase in pressure drop during filtration.

2. At a low addition level of $0.5 \mathrm{~kg} / \mathrm{ton}$, the grain refiner particles do not affect the filtration performance

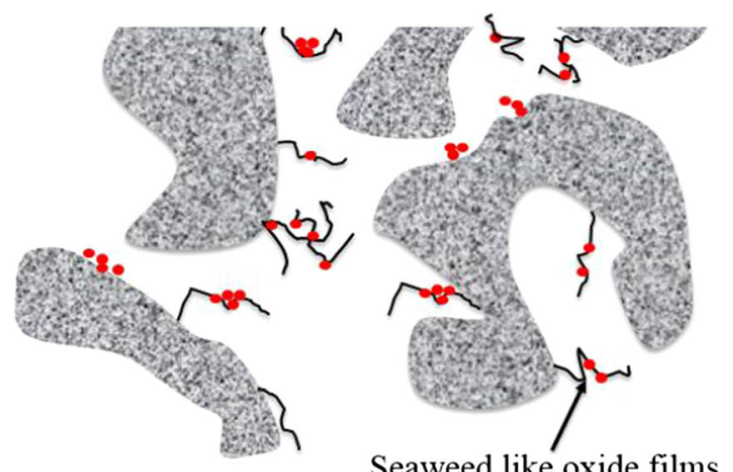

Seaweed like oxide films

Fig. 9-A schematic of the interaction of grain refiner particles and oxide films above and inside the filter. (a) Above the filter, the oxide films will combine with the $\mathrm{TiB}_{2}$ particles, which change the mass and the shape. This may cause and increase in impact and inertial force during filtration. Furthermore, the oxide films formed a cake layer at the filter surface. (b) During filtration, the already existed oxide film bridge or seaweed-like films may be destroyed by the bombardment of grain refiner particles or other inclusions. The weight increase will also cause the already caught inclusions to re-enter the melt. 


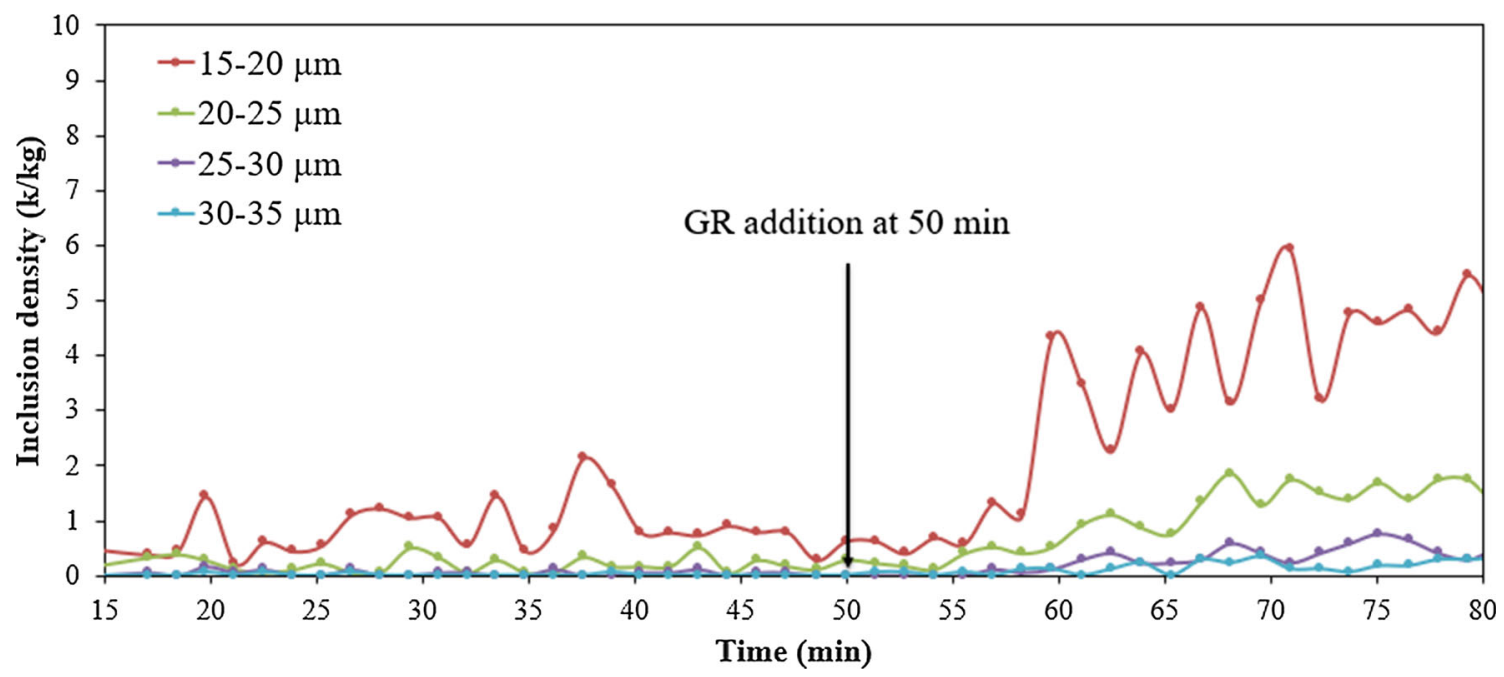

Fig. 10 - The density of inclusions for the size from 15 to $35 \mu \mathrm{m}$ after the filter with $2.0 \mathrm{~kg} /$ ton grain refiner and $50 \mathrm{~kg}$ chips addition, by 80 PPi filter (test-4). The inclusion size group $15-20 \mu \mathrm{m}$ is most severely affected by the grain refiner addition.

regardless of inclusion level in the melt for both 50 $\mathrm{PPi}$ and $80 \mathrm{PPi}$ filters. For aluminum melts with high inclusion loads, an addition of high-level grain refiners $(2.0 \mathrm{~kg} /$ ton $)$ significantly reduces the filter performance. The inclusions in size of $15-20 \mu \mathrm{m}$ dominate the post-filtration inclusions.

3. For aluminum melt with ultra-high inclusion loads $(\mathrm{N} 20>11 \mathrm{k} / \mathrm{kg}$ ), the addition of grain refiner particles up to $2.0 \mathrm{~kg} /$ ton does not influence the filter performance of 80 PPi filters.

4. It is found that the aluminum oxide films in the melt play important roles during melt filtration. The oxide films can form inclusion film bridges on the opening of filter pores and tend to adhere onto the wall of filter, capturing other inclusions and $\mathrm{TiB}_{2}$ particles, and therefore increasing the efficiency of depth mode during filtration. When aluminum melt contains ultra-high level of oxide films, oxide films can form thick cake layers at the top screen of 80 PPi filters, significantly increasing the filter performance.

5. No inclusion particle bridges were observed in the spent filter, but seaweed-like oxide films were observed. It is suggested that the reduction of filtration performance of filters by addition of grain refiner particles is not due to the destroying effect of $\mathrm{TiB}_{2}$ grain refiner particles on the particle bridges in the filter. Instead, the reduction of efficiency is due to the strong adherence of $\mathrm{TiB}_{2}$ particles to oxide films in the filter. The adherence and agglomeration of heavy grain refiner particles onto light oxide films counter the gravitation number of oxide films, making them difficult to be filtrated by CFF. Even though grain refiner particles are too small to be detected, their agglomeration with oxide film can be easily detected by LiMCA.

\section{ACKNOWLEDGMENTS}

This research was carried out as part of the Norwegian Research Council (NRC)-funded BIA-IPN Project $(256724 / \mathrm{O} 20)$ SmartAl. It includes the following partners: Hydro Aluminum AS, Hydal Aluminum Profiler AS, Hycast AS, Ekornes ASA, NTNU, and SINTEF. Funding by the industrial partners and NRC is gratefully acknowledged. On behalf of all authors, the corresponding author states that there is no conflict of interest.

\section{FUNDING}

Open access funding provided by NTNU Norwegian University of Science and Technology (incl St. Olavs Hospital - Trondheim University Hospital).

\section{OPEN ACCESS}

This article is licensed under a Creative Commons Attribution 4.0 International License, which permits use, sharing, adaptation, distribution and reproduction in any medium or format, as long as you give appropriate credit to the original author(s) and the source, provide a link to the Creative Commons licence, and indicate if changes were made. The images or other third party material in this article are included in the article's Creative Commons licence, unless indicated otherwise in a credit line to the material. If material is not included in the article's Creative Commons licence and your intended use is not permitted by statutory regulation or exceeds the permitted use, you will need to obtain permission directly from the copyright holder. To view a copy of this licence, visit http://creativec ommons.org/licenses/by/4.0/. 


\section{REFERENCES}

1. L. Liu and F.H. Samuel: J. Mater. Sci., 1997, vol. 32 (22), pp. 5901-25.

2. C. Simensen: Aluminium, 1980, vol. 56 (5), pp. 335-40.

3. T.A. Engh and G.K. Sigworth: in Essential Readings in Light Metals: Volume 3 Cast Shop for Aluminum Production, J.F. Grandfield, and D.G. Eskin, eds. 2016, Springer International Publishing: Cham. pp. 208-17.

4. B.-D. Sun, W.-J. Ding, D. Shu, and Y.-H. Zhou: J. Cent. South Univ. Technol., 2004, vol. 11 (2), pp. 134-41.

5. M. Zhou, K. Li, B.D. Sun, D. Shu, H.J. Ni, and J. Wang: $J$. Mater. Sci. Lett., 2002, vol. 21 (16), pp. 1285-87.

6. S. Makarov, R. Ludwig, and D. Apelian: IEEE Trans Magn., 2000, vol. 36 (4), pp. 2015-21.

7. G. Song, B. Song, Z. Yang, Y. Yang, and J. Zhang: Metall Mater. Trans. B, 2016, vol. 47B, pp. 3435-45.

8. L.N.W. Damoah and L. Zhang: Metall Mater. Trans. B, 2010, vol. 41B, pp. 886-907.

9. F. Frisvold, T.A. Engh, S.T. Johansen, and T. Pedersen: in Essential Readings in Light Metals: Volume 3 Cast Shop for Aluminum Production, J.F. Grandfield, and D.G. Eskin, eds. 2016, Springer International Publishing: Cham. pp. 324-31.

10. A. Engelbrecht: Minerals, Metals and Materials Society/AIME, Warrendale, 2010.

11. H. Görner, Ph.D. Thesis, Norwegian University of Science and Technology, 2009.

12. S. Ray, B. Milligan, and N. Keegan: Aluminium Cast House Technology, 2005: pp. 1-12.

13. C. Tian, and R. Guthrie: Light Metals 1995, Las Vegas, 1995. 12(16).

14. C. Tian and R.I.L. Guthrie: Metall. Mater. Trans. B, 1995, vol. 26B, pp. 537-46.

15. C. Voigt, E. Jäckel, F. Taina, T. Zienert, A. Salomon, G. Wolf, C.G. Aneziris, and P. Le Brun: Metall Mater. Trans. B, 2017, vol. 48B, pp. 497-505.

16. S. Bao, K. Tang, A. Kvithyld, T. Engh, and M. Tangstad: Trans. Nonferr. Metal Soc., 2012, vol. 22 (8), pp. 1930-38.

17. S. Bao, T.A. Engh, M. Syvertsen, A. Kvithyld, and M. Tangstad: J. Mater. Sci., 2012, vol. 47 (23), pp. 7986-98.

18. S. Bao, M. Syvertsen, A. Nordmark, A. Kvithyld, T. Engh, and M. Tangstad: in Light Metals 2013, B.A. Sadler, ed. 2016, Springer International Publishing: Cham. pp. 981-986.

19. H. Duval, C. Rivière, E. Laé, P. Le Brun, and J.-B. Guillot: Metall. Mater. Trans. B, 2009, vol. 40B, p. 233.

20. L.J. Gauckler, M.M. Waeber, C. Conti, and M. Jacob-Duliere: JOM, 1985, vol. 37 (9), pp. 47-50.

21. C. Rivière, H. Duval, and J.B. Guillot: TMS Light Metals, 2004: pp. 761-66.

22. N.G. Towsey, W. Schneider, and H.-P. Krug. Aluminium Cast House Technology (Seventh Australasian Conference). 2013. Wiley.

23. P. Netter, and C. Conti: in Essential Readings in Light Metals. Volume 3 Cast Shop for Aluminum Production, J.F. Grandfield and D.G. Eskin, eds. 2016, Springer International Publishing, Cham. pp. 271-84.

24. N. Keegan, W. Schneider, and H.-P. Krug: Light Metals-Warrendale, 1999, pp. 1031-40.
25. N. Towsey, W. Schneider, H.-P. Krug, A. Hardman, and N.J. Keegan: in Essential Readings in Light Metals: Volume 3 Cast Shop for Aluminum Production, J.F. Grandfield and D.G. Eskin, eds. 2016, Springer International Publishing, Cham. pp. 291-95.

26. N. Towsey, W. Schneider, H.-P. Krug, A. Hardman, and N.J. Keegan, in Continuous Casting, K. Ehrke and W. Schneider, eds. 2006, Wiley-VCH Verlag GmbH \& Co. KGaA, pp. 26-32.

27. N.J. Keegan, W. Schneider, H.-P. Krug, and V. Dopp, Light Metals-Warrendale, 1997, pp. 973-82.

28. E. Laé, H. Duval, C. Rivière, P. Le Brun, and J.-B. Guillot: in Essential Readings in Light Metals: Volume 3 Cast Shop for Aluminum Production, J.F. Grandfield and D.G. Eskin, eds. 2016, Springer, Cham. pp. 285-90.

29. U. Tundal, I. Steen, A. Strømsvåg, T. Haugen, J.O. Fagerlie, and A. Håkonsen. 2019. Springer International Publishing, Cham.

30. C. Voigt, B. Fankhänel, B. Dietrich, E. Storti, M. Badowski, M. Gorshunova, G. Wolf, M. Stelter, and C. Aneziris: Metall. Mater. Trans. B, 2020.

31. S. Bao: Filtration of aluminium-experiments, wetting and modelling. 2011.

32. R. Wakeman, and S. Tarleton: Solid/liquid Separation: Principles of Industrial Filtration. Elsevier, 2005.

33. C. Tian, D. Mazumdar, and R.I.L. Guthrie: Metall. Mater. Trans. B, 1999, vol. 30B, pp. 891-900.

34. M.W. Kennedy, K. Zhang, R. Fritzsch, S. Akhtar, J.A. Bakken, and R.E. Aune: Metall. Mater. Trans. B, 2013, vol. 44B, pp. 67190.

35. Melt Refining and Impurity Control, in Direct-Chill Casting of Light Alloys. 2013. p. 56-102.

36. L.J. Gauckler, M.M. Waeber, C. Conti, and M. Jacob-Dulière, in Essential Readings in Light Metals: Volume 3 Cast Shop for Aluminum Production, J.F. Grandfield and D.G. Eskin, eds. 2016, Springer International Publishing, Cham. pp. 251-262.

37. J. Yang, S. Bao, S. Akhtar, P. Shen, and Y. Li: Metall. Mater. Trans. B, 2020: p. 1-11.

38. J. Yang, S. Bao, S. Akhtar, and Y. Li: Metall. Mater. Trans. B, 2021, vol. 52, pp. 2497-508.

39. M. Gökelma, P. Le Brun, T. Dang, M. Badowski, J. Morscheiser, B. Friedrich, and S. Tewes: in Light Metals 2016, E. Williams, ed. 2016, Springer International Publishing, Cham, pp. 843-48.

40. B. Friedrich, C. Kräutlein, and K. Krone: in Continuous Casting. 2006, Wiley-VCH Verlag GmbH \& Co. KGaA. pp. 1-22.

41. F. Heuzeroth, J. Fritzsche, and U.A. Peuker: Particuology, 2015, vol. 18 , pp. $50-57$.

42. N.V. Buchilin, V.G. Maksimov, and V.G. Babashov: Glass Ceram., 2015, vol. 72 (7), pp. 246-52.

43. S. Poynton, M. Brandt, and J. Grandfield: Light Metals. 2009. Wiley.

44. D.C. Chesonis, in Light Metals 2017, A.P. Ratvik, ed. 2017, Springer International Publishing, Cham. pp. 1411-17.

45. Y. Xu, D. Casari, R.H. Mathiesen, and Y. Li: Acta Mater., 2018, vol. 149 , pp. $312-25$.

Publisher's Note Springer Nature remains neutral with regard to jurisdictional claims in published maps and institutional affiliations. 